\title{
VALORES SÉRICOS DE CÁLCIO, FÓSFORO, SÓDIO, POTÁSSIO E PROTEÍNAS TOTAIS EM CAPRINOS FÊMEAS DA RAÇA PARDA ALPINA
}

\author{
SERUM VALUES OF CALCIUM, PHOSPHORUS, SODIUM, POTASSIUM AND TOTAL PROTEINS \\ SERUM LEVELS IN ALPINE DOES AND DOELINGS
}

\author{
Graziela Barioni $^{1}$ Joandes Henrique Fonteque ${ }^{2}$ Paulo Ricardo de Oliveira Paes ${ }^{2}$ \\ Regina Kiomi Takahira ${ }^{3}$ Aguemi Kohayagawa $^{4}$ Raimundo Souza Lopes $^{3}$ \\ Sônia Terezinha dos Anjos Lopes ${ }^{1}$ Adalberto José Crocci ${ }^{5}$
}

RESUMO

Por ser de grande importância o conhecimento de valores séricos referenciais do mineralograma e do proteinograma, a sua utilização na medicina veterinária, e a escassez de trabalhos brasileiros relacionados à espécie caprina, este estudo objetivou determinar e comparar os níveis séricos de cálcio, fósforo, sódio, potássio e proteínas (proteína total, albumina, globulina e a relação albumina/globulina) em caprinos fêmeas da raça Parda Alpina, em três idades diferentes. Foram utilizadas 30 fêmeas caprinas da raça Parda Alpina criadas em regime intensivo, sendo separadas em três grupos: Grupo 1 - 10 fêmeas jovens com idade de quatro meses; Grupo 2 - 10 fêmeas adultas jovens com idade de 18 meses; Grupo 3 - 10 fêmeas adultas lactantes com idade de 24 a 60 meses. Os animais foram avaliados por meio de exames clínico e coproparasitológico. Foram encontrados os seguintes valores médios de cálcio, fósforo, sódio

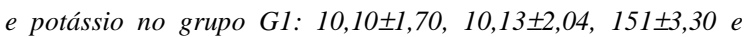
$5,16 \pm 0,41$; no grupo $G 2$ : $10,36 \pm 0,94,7,49 \pm 1,34,145,9 \pm 3,35 e$ 4,56 $\pm 0,48$; e para o grupo $G 3: 9,47 \pm 1,45,5,90 \pm 1,21,153,3 \pm 5,17$ e 4,20 $\pm 0,55$. Para as variáveis proteína total sérica, albumina, globulina e relação albumina/globulina foram encontrados os seguintes valores médios, para o grupo G1: 6,29 $\pm 0,94$,

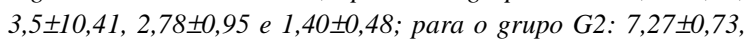
$4,92 \pm 1,06,3,06 \pm 0,56,1,43 \pm 0,44$; e para o grupo $G 3: 7,14 \pm 0,84$ $3,70 \pm 0,20,3,44 \pm 0,79$ e 1,14 $\pm 0,30$. A análise estatística dos dados demonstra que existe influência da faixa etária nas variáveis fósforo, sódio, potássio, proteína total e albumina.

Palavras-chave: caprinos, cálcio, fósforo, sódio, potássio, proteína total, albumina, globulina.

\section{SUMMARY}

Despite the importance of the knowledge of serum reference values of mineralogram and proteinogram, there is a shortage of studies with goats in Brazil. The objective of this study was to determine and to compare the serum levels of calcium, phosphorus, sodium, potassium, total protein, albumin, globulin, and the albumin/globulin ratio in Parda Alpina goats at three different ages. Thirty Parda Alpina goats raised on an intensive system were utilized. They were divided into three groups: Group 1 - 10 young females (four months old); Group 2 - 10 young adult females (18 months old); Group 3 - 10 adult lactating females (24 to 60 months old). The mean values of calcium, phosphorus, sodium and potassium were 10.10 \pm 1.70 , $10.13 \pm 2.04,151 \pm 3.30$ and $5.16 \pm 0.41$ for G1, 10.36 \pm 0.94 , $7.49 \pm 1.34,145.9 \pm 3.35$ and $4.56 \pm 0.48$ for group 2 and $9.47 \pm 1.45$, $5.90 \pm 1.21,153.3 \pm 5.17$ and $4.20 \pm 0.55$ for G3. For total serum protein, albumin, globulin and the albumin/globulin rate the mean were $6.29 \pm 0.94,3.5 \pm 10.41,2.78 \pm 0.95$ and $1.40 \pm 0.48$, for $G 1,7.27 \pm 0.73,4.92 \pm 1.06,3.06 \pm 0.56,1.43 \pm 0.44$ for group 2 and $7.14 \pm 0.84,3.70 \pm 0.20,3.44 \pm 0.79$ and $1.14 \pm 0.30$ for G3.The statistic analysis demonstrated influence of age on phosphorus, sodium, potassium, total protein and albumin.

Key words: goats, calcium, phosphorus, sodium, potassium, total protein, albumin, globulin.

\section{INTRODUÇÃO}

A bioquímica dos minerais e das proteínas séricas é de primordial importância na avaliação do estado nutricional, podendo indicar alterações meta-

\footnotetext{
${ }^{1}$ Médico Veterinário. Pós-graduando. Faculdade de Medicina Veterinária e Zootecnia (FMVZ), Universidade Estadual de São Paulo (Unesp), CP 560, 18618-000, Botucatu, SP, Brasil. E-mail - gbarioni @ieg.com.br. Autor para correspondência.

${ }^{2}$ Médicos Veterinários, Pós-graduandos, FMVZ - Unesp, Botucatu, SP.

${ }^{3}$ Médico Veterinário, Professor Assistente, FMVZ - Unesp, Botucatu, SP.

${ }^{4}$ Médico Veterinário, Professor Titular, FMVZ - Unesp, Botucatu, SP.

${ }^{5}$ Matemático, Professor Assistente, Instituto Biológico, FMVZ - Unesp, Botucatu, SP.
} 
bólicas e auxiliar no diagnóstico clínico de diversas enfermidades. Para uma interpretação correta dos resultados obtidos, existe a necessidade de se conhecer os valores de referência para as diferentes espécies, raças, sexos e idades de animais criados em diferentes regiões do Brasil e sob diversas condições de manejo.

BEHERA et al. (1993) determinaram em caprinos fêmeas da raça "Black Bengal", que não há diferença significante nos níveis de cálcio e fósforo, considerando-se sexos, mas há diferença em relação às idades de três, seis e maiores que 24 meses. Segundo BHATTACHARYYA et al. (1994), os níveis de cálcio, fósforo, sódio e potássio são significantemente maiores na fase pré-pubere (seis - dez meses), sendo que o aumento dos níveis de cálcio e fósforo pode ser decorrente do crescimento ou devido à alta taxa de absorção pelo trato gastrointestinal. Com a idade, ocorre um decréscimo na concentração de sódio e potássio.

De acordo com JANA et al. (1991), em cabras da raça "Black Bengal", há uma diminuição dos níveis de sódio e fósforo, do terço final de gestação até o parto, e de cálcio, somente no final da gestação. As fases da gestação também influenciam os níveis de potássio sérico. Do mesmo modo, SINGH et al. (1994) demonstraram que os níveis de cálcio e fósforo não sofrem influência com a fase do ciclo estral.

CASTRO et al. (1977a,b), em estudo utilizando cabras da raça "Pygmy" com 12 a 24 meses de idade, observaram diferença entre faixas etárias e determinaram os níveis séricos de cálcio, fósforo, sódio, potássio, proteína total, albumina, globulina e a relação albumina/globulina.

KANEKO et al. (1997) determinaram os valores médios para os níveis de cálcio, fósforo, sódio, potássio e proteína total para a espécie caprina, sendo que esses dados são amplamente utilizados na rotina, porém valores de referência são necessários para animais de diferentes raças, idades, manejo e estado fisiológico. O objetivo do presente trabalho foi determinar e comparar os níveis séricos de cálcio, fósforo, sódio, potássio e proteínas (proteína total, albumina e globulina, e a relação albumina/globulina) em fêmeas caprinas jovens, adultas jovens e adultas lactantes, da raça Parda Alpina, clinicamente sadias.

\section{MATERIAL E MÉTODOS}

Foram utilizadas 30 fêmeas caprinas da raça Parda Alpina, criadas na fazenda Lageado, da Faculdade de Medicina Veterinária e Zootecnia (FMVZ), UNESP- Botucatu, SP, em regime intensivo, recebendo no cocho capim elefante triturado, concentrado e sal mineral comercial (Fosbovi $20^{\circledR}$ ). As cabras em lactação recebiam suplementação de $1 \mathrm{~kg}$ de concentrado no momento da ordenha. Os animais foram divididos em três grupos: Grupo 1 - 10 fêmeas jovens com idade de quatro meses; Grupo 2 - 10 fêmeas adultas jovens com idade de 18 meses; Grupo 3 - 10 fêmeas adultas lactantes com idades de 24 a 60 meses. Os animais foram avaliados por meio de exames clínico e coproparasitológico.

Obtiveram-se, mediante venipunção da jugular, cinco $\mathrm{m} \ell$ de sangue em tubos de colheita a vácuo e sem anticoagulante, sendo o soro separado por centrifugação para posterior análise laboratorial. A determinação dos níveis de cálcio, fósforo, proteínas totais e albumina foi realizada por métodos colorimétricos (Celm E 210 D), utilizando-se Kits comerciais $\left(\right.$ Labtest $\left.^{\circledR}\right)$ e os níveis de sódio e potássio por fotometria de chama (Celm FC 280). Obteve-se o valor de globulina pela diferença entre os valores de proteína total e albumina sérica.

A avaliação estatística foi feita pela análise de variância de um delineamento inteiramente casualizado, com três tratamentos, caracterizados pelas faixas etárias com 10 repetições. O teste de comparação múltipla de médias utilizado foi de Student-Newman-Keuls em nível de 5\% de significância (ZAR, 1996). Foram obtidos os coeficientes de correlação linear de Pearson entre as variáveis de interesse e apresentado o valor de significância.

\section{RESULTADOS E DISCUSSÃO}

Os valores de média $(\overline{\mathrm{X}})$, desvio padrão (s), mínimo (V. min.) e máximo (V. máx.) das variáveis cálcio, fósforo, sódio, potássio, proteína total, albumina e globulina séricas, e relação albumina/globulina encontram-se descritos nas tabelas 1 e 2 .

A análise da variável cálcio não determinou diferença estatisticamente significante $(\mathrm{p}<0,05)$ entre os valores médios dos grupos G1, G2 e G3, sendo semelhantes àqueles relatados por BEHERA et al. (1993), para caprinos fêmeas da raça "Black Bengal". Com relação à variável fósforo, foi observada diferença estatisticamente significante $(p<0,05)$ entre os valores médios dos grupos G1, G2 e G3, sendo os valores superiores encontrados nos animais jovens (grupos G1 e G2) e inferiores nos adultos (grupo G3). Os valores médios de cálcio e fósforo obtidos nos grupos G1, G2 e G3 foram superiores aos relatados por CASTRO et al. (1977a), para caprinos da raça "Pygmy" com idade de 1 a 2 anos. 
Tabela 1 - Valores de média (x), desvio padrão (s), mínimo (V.min.) e máximo (V.máx.) de cálcio, fósforo, sódio e potássio de caprinos fêmeas da raça Parda Alpina com idades de quatro meses (G1), 18 meses (G2) e 24 a 60 meses (G3).

\begin{tabular}{lrrrrrrrrrrrrr}
\hline & \multicolumn{3}{c}{ Cálcio $(\mathrm{mg} / \mathrm{d} \ell)$} & \multicolumn{3}{c}{ Fósforo $(\mathrm{mg} / \mathrm{d} \ell)$} & \multicolumn{3}{c}{ Sódio $(\mathrm{mg} / \mathrm{d} \ell)$} & \multicolumn{3}{c}{ Potássio $(\mathrm{mg} / \mathrm{d} \ell)$} \\
\hline & $\mathrm{G} 1$ & $\mathrm{G} 2$ & $\mathrm{G} 3$ & $\mathrm{G} 1$ & $\mathrm{G} 2$ & $\mathrm{G} 3$ & $\mathrm{G} 1$ & $\mathrm{G} 2$ & $\mathrm{G} 3$ & $\mathrm{G} 1$ & $\mathrm{G} 2$ & $\mathrm{G} 3$ \\
$\mathrm{x}$ & 10,10 & 10,36 & 9,47 & 10,13 & 7,49 & 5,90 & 151,0 & 145,9 & 153,3 & 5,16 & 4,56 & 4,20 \\
$\mathrm{~s}$ & 1,70 & 0,94 & 1,45 & 2,04 & 1,34 & 1,21 & 3,30 & 3,35 & 5,17 & 0,41 & 0,48 & 0,55 \\
V.mín. & 6,70 & 8,90 & 7,40 & 7,60 & 5,40 & 4,00 & 144,0 & 142,0 & 143,0 & 4,60 & 4,00 & 3,00 \\
V.máx. & 12,80 & 11,90 & 12,80 & 14,50 & 9,40 & 7,70 & 155,0 & 151,0 & 159,0 & 5,90 & 5,60 & 4,90 \\
\hline
\end{tabular}

sendo que no grupo G2 os valores foram, respectivamente, semelhantes e superiores aos obtidos por CASTRO et al. (1977a,b).

Os níveis de sódio podem ser influenciados tanto pela

Nos grupos G1, G2 e G3, os valores médios obtidos para a variável cálcio e, no grupo G3, para a variável fósforo, encontram-se dentro dos limites de referência propostos por KANEKO et al. (1997), enquanto que nos grupos G1 e G2, os valores para a variável fósforo estão acima do limite superior.

O fato dos valores de cálcio e fósforo serem superiores nos animais jovens deve-se a estes apresentarem uma maior eficiência na absorção desses minerais em decorrência da alta taxa de desenvolvimento ósseo, justificado pela maior reabsorção renal e maior mobilização óssea do fósforo em animais em crescimento (THONPSON \& WERNER, 1976; HORST, 1994; KINCAID, 1988).

De acordo com os valores encontrados neste experimento, a relação cálcio:fósforo obtida para os grupos G1, G2 e G3 foi, respectivamente, $1: 1 ; 1,4: 1$ e $1,6: 1$, demonstrando um aumento gradativo no decorrer do crescimento. Segundo CONRAD et al. (1985), e McDOWELL (1992), a proporção sérica ideal entre cálcio e fósforo para o crescimento e formação dos ossos é de 1:1 a 2:1. Demonstra-se, então, que esses animais apresentam uma adequada proporção desses minerais para a idade.

$\mathrm{Na}$ análise dos valores médios das variáveis sódio e albumina, constatou-se diferença estatisticamente significante $(\mathrm{p}<0,05)$ entre os grupos G1 e G2 e G2 e G3, e para as variáveis potássio e proteínas totais séricas entre os grupos G1 e G2 e G1 e G3. Os valores médios obtidos na avaliação das variáveis sódio e potássio situam-se dentro dos limites de referência segundo KANEKO et al. (1997), idade como pelos níveis de potássio e cloreto, e ainda pelo estresse, lactação, prenhez, crescimento e alterações no equilíbrio hidroeletrolítico e osmótico (HENRY, 1995; BARIONI, 1999). A diminuição dos níveis séricos de potássio podem ser decorrentes da baixa taxa de absorção relacionada com o avanço da idade (BHATTACHARYYA $\boldsymbol{e t} \boldsymbol{a l}$., 1994).

Em relação às proteínas séricas, os valores médios das variáveis proteína total do grupo G1, albumina dos grupos G1 e G3 e globulina dos grupos G1, G2 e G3 encontram-se dentro dos limites de referência para a espécie, descritos por KANEKO $\boldsymbol{e t}$ al. (1997), enquanto os valores médios da variável proteína total sérica nos grupos G2 e G3 estão acima destes limites.

A elevação dos níveis de globulina e a diminuição da relação albumina/globulina observadas no experimento, demonstram que as proteínas totais aumentam com a idade, decorrente de uma diminuição da albumina e elevação da globulina (LIBERG, 1977; JAIN, 1993). No grupo de animais em lactação, houve aumento das globulinas e diminuição da albumina como relatado por KANEKO $\boldsymbol{e} t$ al. (1997).

As diferenças dos valores obtidos neste trabalho para as variáveis cálcio e fósforo, assim como para as demais variáveis, em relação aos descritos por outros autores para animais da mesma espécie, refletem a influência de fatores como raça, manejo, nutrição e estado fisiológico.
Tabela 2 - Valores de média (x), desvio padrão (s), mínimo (V.min.) e máximo (V.min.) de proteína total sérica, albumina, globulina e relação albumina/globulina $(\mathrm{A} / \mathrm{G})$ de caprinos fêmeas da raça Parda Alpina com idades de quatro meses (G1), 18 meses (G2) e 24 a 60 meses (G3).

\begin{tabular}{lccccccccccccc}
\hline & \multicolumn{3}{c}{ Proteína Total $(\mathrm{g} / \mathrm{d} \ell)$} & \multicolumn{3}{c}{ Albumina $(\mathrm{g} / \mathrm{d} \ell)$} & \multicolumn{3}{c}{ Globulina $(\mathrm{g} / \mathrm{d} \ell)$} & \multicolumn{4}{c}{ A/G } \\
\hline & $\mathrm{G} 1$ & $\mathrm{G} 2$ & $\mathrm{G} 3$ & $\mathrm{G} 1$ & $\mathrm{G} 2$ & $\mathrm{G} 3$ & $\mathrm{G} 1$ & $\mathrm{G} 2$ & $\mathrm{G} 3$ & $\mathrm{G} 1$ & $\mathrm{G} 2$ & $\mathrm{G} 3$ \\
$\mathrm{x}$ & 6,29 & 7,27 & 7,14 & 3,51 & 4,92 & 3,70 & 2,78 & 3,06 & 3,44 & 1,40 & 1,43 & 1,14 \\
s & 0,94 & 0,73 & 0,84 & 0,41 & 1,06 & 0,20 & 0,95 & 0,56 & 0,79 & 0,48 & 0,44 & 0,30 \\
V.mín. & 5,27 & 6,36 & 5,81 & 2,83 & 4,00 & 3,38 & 1,79 & 2,42 & 2,16 & 0,79 & 0,99 & 0,77 \\
V.máx. & 7,99 & 8,54 & 7,99 & 4,00 & 6,41 & 4,02 & 4,16 & 4,11 & 4,52 & 2,01 & 2,53 & 1,69 \\
\hline
\end{tabular}

\section{CONCLUSÕES}

A partir dos dados obtidos neste trabalho, pode-se concluir que, em fêmeas caprinas da raça Parda Alpina, ocorre influência da faixa etária em relação à variável fósforo, 
sendo que os valores decrescem com a idade. Os animais jovens apresentam os maiores níveis séricos de potássio e os mais baixos de proteína total, e as adultas jovens, os menores níveis de sódio e os mais elevados de albumina. Não há influência da idade sobre os níveis séricos de cálcio, globulina e relação albumina/globulina.

\section{REFERÊNCIAS BIBLIOGRÁFICAS}

BARIONI, G. Influência dos fatores etários e sexuais nos valores séricos de cálcio, fósforo, magnésio, sódio e potássio em bovinos Nelore (Bos indicus, Linnaeus, 1758), criados na região de Botucatu, Estado de São Paulo. Botucatu, 1999. 86p. Dissertação (Mestrado em Medicina Veterinária) - Faculdade de Medicina Veterinária e Zootecnia, Universidade Estadual Paulista, 1999.

BEHERA, P.C., BISOI, P.C., MOHANTY, B.P., et al. Clinically important serum constituents of black bengal goats. Indian Vet J, v.70, p.713-717, 1993.

BHATTACHARYYA, B.N., TALUKDER, S.C., BARUAH, R.N., et al., Influence of age on macro elements status of non-descript goat. Indian Vet J, v.71, p.338-340, 1994

CASTRO, A., DHINDSA, D.S., HOVERSLAND, A.S., et $\boldsymbol{a l}$. Serum electrolytes in normal pygmy goats. Am J Vet Res, v.38, n.5, p.663-664, 1977a.

CASTRO, A., DHINDSA, D.S., HOVERSLAND, A.S., et al. Serum proteins and protein electrophoretic pattern in normal pygmy goats. Am J Vet Res, v.38, n.5, p.665-667, 1977b.

CONRAD, J.H., McDOWELL, L.R., ELLIS, G.L., et al. Minerais para ruminantes em pastejo em regiões tropicais. Campo Grande : EMBRAPA, 1985. 90p.

HENRY, P.R. Sodium and chlorine bioaviability. In: AMNERMAN, C.B., BAKER, D.H., LEWIS, A.J. Bioaviability of nutrients for animals: amino acids, minerals, vitamins. San Diego : Academic, 1995. p.337348

HORST, R.L., GOFF, J.P., RIEINHARDT, T.A. Calcium and vitamin D metabolism in the dairy cow. J Dairy Sci, v.77, p.1936-1951, 1994.

JAIN, N.C. Essentials of veterinary hematology. Philadelphia: Lea \& Febinger, 1993. 417p.

JANA, S., BHATTACHARYYA, B., DUTTAGUPTA, R., $\boldsymbol{e}$ t al. A note on some biochemical constituents of blood in pregnant goats reared on extensive manegement system. Indian Vet J, v.68, p.592-4, 1991

KANEKO, J.J., HARVEY, J.W., BRUSS, M.L. Clinical biochemistry of domestic animals. San Diego : Academic. 1997. p.932.

KINCAID, R. Macroelementos para los ruminantes. In CHURCH, D.C. El ruminant: fisiología digestiva y nutricíon. Zaragoza : Acribia, 1988. p.373-390.

LIBERG, P. Agarose gel electrophoresis fractionation of serum proteins in adult cattle. I. A study of clically healthy cows. Acta Vet Scand., v.18, p.40-53, 1977

McDOWELL, L.R. Minerals in animal and human nutrition. San Diego : Academic, 1992. 524p.

SINGH, V., BUGALIA, N.S., KUMAR, P. Biochemical variations on plasmatic total protein, cholesterol and minerals during oestrus cycle in goats (Capra hircus). Indian Vet $\mathbf{J}$, v.71, p.666-669, 1994.

THONPSON, D.J., WERNER, J.C. Cálcio, fósforo e flúor na nutrição animal. In: SIMPÓSIO LATINO-AMERICANO SOBRE PESQUISA EM NUTRIÇÃO MINERAL DE RUMINANTES EM PASTAGENS, 1976, Belo Horizonte. Anais... Belo Horizonte : UFMG/UFV/EPAMIG, 1976. p.85-98.

ZAR, J.H. Biostatistical analysis. New Jersey : Prentice-Hall: Upper Saddle River, 1996. p.718.

Ciência Rural, v. 31, n. 3, 2001. 